\title{
A Fatal Case of a Paint Thinner Ingestion
}

\section{Comparison Between Toxicological and Histological Findings}

\author{
Antonina Argo, MD, * David Bongiorno, PhD, $†$ Antonino Bonifacio, MD, * Valentina Pernice, * \\ Rosa Liotta, MD, PhD, * Serena Indelicato, PhD, † Stefania Zerbo, MD, * Pierangela Fleres, MD, * \\ Leopoldo Ceraulo, PhD, $\dagger$ and Paolo Procaccianti, MD*
}

\begin{abstract}
Toluene and xylene are aromatic hydrocarbons commonly used as an industrial solvent for the manufacturing of pharmaceuticals, paints, and chemicals. The Occupational Safety and Health Administration has determined that toluene levels of 2000 parts per million ( $\mathrm{ppm})$ are considered dangerous to life and health. Several studies have examined the absorption of toluene and xylene following inhalation and oral ingestion in humans. Volatile organic compounds that are absorbed into the blood are distributed throughout the body; in particular, distribution of absorbed toluene and xylene in humans and rodents is characterized by preferential uptake in well-perfused and lipophil tissues such as the brain, liver, lungs, and body fat and also in central nervous system. The available studies indicate that xylenes are rapidly absorbed independently from the kind of exposition. We illustrate a fatal case of self-poisoning by ingestion of varnishes diluting solvents, reporting the identification and quantification of volatile organic compounds (toluene, o-m-p xylene) from human biologic liquids and viscera samples using the Solid-Phase Microextraction-Headspace-Gas Chromatography/Mass Spectrometry to toxicological analysis, and the histopathological findings evaluated in liver, kidney, and lungs.
\end{abstract}

Key Words: toluene, xylene, paint thinner ingestion, self poisoning, varnish-diluting solvents

(Am J Forensic Med Pathol 2010;31: 186-191)

$T^{2}$ oluene and xylene are aromatic hydrocarbons $\left(\mathrm{C}_{7} \mathrm{H}_{8}\right.$ and $\left.\mathrm{C}_{8} \mathrm{H}_{10}\right)$ commonly used as an industrial solvent for the manufacturing of pharmaceuticals, paints, and chemicals. The Occupational Safety and Health Administration has determined the acceptable level of occupational exposure to toluene and xylene for people in the workplace; toluene levels of $2000 \mathrm{ppm}$ are considered dangerous to life and health.

Several studies have examined the absorption of toluene and xylene following inhalation and oral ingestion in humans; volatile organic compounds (VOC's) that are absorbed into the blood are distributed throughout the body.

Distribution of absorbed toluene and xylene in humans and rodents is characterized by preferential uptake in well-perfused and lipophil tissues such as the brain, liver, lungs, and body fat. Data from literature suggest that, after oral ingestion, toluene accumulates in the liver, whereas after inhalation toluene accumulates the brain. ${ }^{1}$

Studies in humans and animals show that the central nervous system is also the main target of xylenes. ${ }^{2}$ The various isomers o-, $\mathrm{m}$-, p-xylenes have similar health effects.

Manuscript received June 27, 2008; accepted January 4, 2009.

From the *Departments of Biotechnology and Legal Medicine and $\dagger$ Chemical and Pharmaceutical Technologies, University of Palermo, Palermo, Italy.

Reprints: Antonina Argo, MD, Department of Biotechnology and Legal Medicine,

University of Palermo, Palermo, Italy. E-mail: antonella.argo@libero.it.

Copyright (C) 2010 by Lippincott Williams \& Wilkins

ISSN: 0195-7910/10/3102-0186

DOI: $10.1097 /$ PAF.0b013e3181c6c11f
The available studies indicate that xylenes are rapidly absorbed independently from the kind of exposition; once absorbed the toxics undergo a considerable metabolism, being the liver the primary site of such metabolism and hippuric acid the main metabolite. ${ }^{2}$

As concerns quantification of VOCs in postmortem matrices several methods have been proposed.

These substances have been generally determined by gas chromatography after extracting the compounds using solvent extraction methods or even static and dynamic headspace (HS) techniques. ${ }^{3}$

The headspace techniques include HS-solid phase microextraction (HS-SPME), cryogenic oven trapping (HS-COT), cryogenic focusing (HS-CF), and purge and trap. ${ }^{4-10}$

SPME has proved to be an excellent sampling technique for analysis of volatile organic compounds. In fact, SPME is solventfree and require only minimal sample handling and preparation. These technique uses polymer coated/fused-silica fibers for the extraction ${ }^{11,12}$ of organic compounds from different matrices.

\section{CASE REPORT}

A 15-year-old white boy was found in supine position in the garden of his Teacher's country-house. The student was immediately taken to the local emergency room and, after a few minutes, he was pronounced dead.

History indicated that the boy, after failing an examination, had gone to his teacher, to talk to him. After a few minutes, the boy fell on his back, with agonal gurgling and foam in his mouth. After his death, the local police-officers found numerous small bottles of varnish-diluting solvents.

By an order of the legal authorities, the external examination and the autopsy were performed 2 days later at the Institute of Legal Medicine of Palermo.

External examination: the young boy was $175 \mathrm{~cm}$ tall and his weight was $65 \mathrm{~kg}$. No injuries were found in his body; only a nasal hemorrhage and labial and subungual cyanosis were found.

\section{MATERIALS AND METHODS}

\section{Autopsy Findings}

The forensic autopsy revealed cerebral edema and congestion of cerebral veins. There were no lesions in the scalp or the galea capitis and no intracerebral hemorrhage. Pulmonary edema and pancreatic and renal congestion were found. The gastric content was brownish liquid $(300 \mathrm{~mL})$ and had an odor of organic solvent. Nothing else was found during the autopsy. The blood alcohol screening was negative. Urine samples were too exiguous to perform any analytical screening.

\section{Histologic Findings}

Samples of organs taken during autopsy were fixed in buffered formalin $10 \%$ for a period of 2 weeks and then processed. From blocks obtained, sections thick 4 to $6 \mu \mathrm{m}$ were cut and colored with hematoxylin-eosin. The microscopic examination showed severe cerebral 


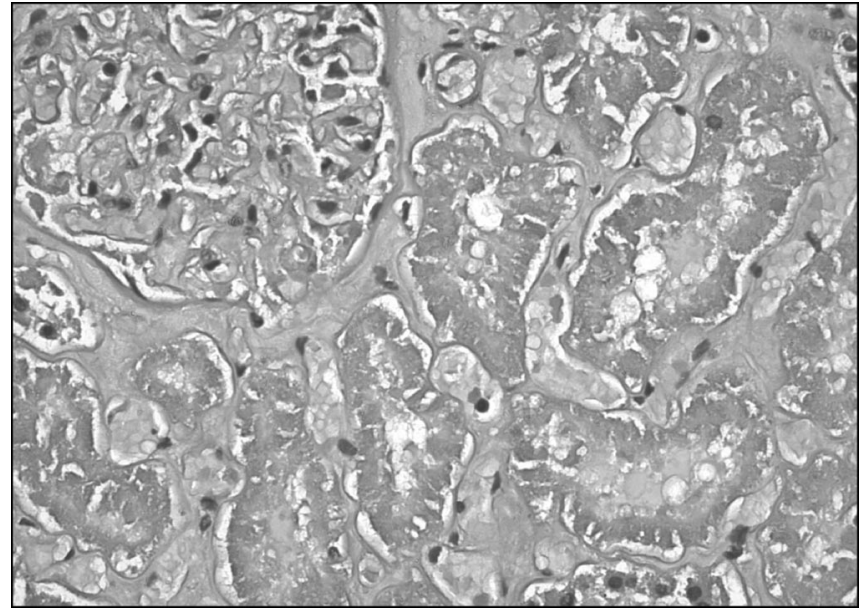

FIGURE 1. (EE 200×) Renal parenchyma with diffuse acute tubular necrosis.

edema, diffuse axonal damage, diffuse cytotoxic edema, and multifocal ischemic neuronal injury. Renal parenchyma showed cellular swelling and tubular necrosis (Fig. 1). Hepatic parenchyma showed diffuse vacuolar degeneration of hepatocytes and vascular congestion (Fig. 2).

Diffuse vascular congestion, intra-alveolar hemorrhage, and edema were observed in pulmonary slides (Fig. 3). Most part of red blood cells was lysed and alveolar septa were fragmented probably due to direct solvent activity on cellular membranes. The microscopic examination of esophagus showed multifocal erosion of epithelium and severe vascular congestion and edema of mucous and submucous membranes.

\section{Toxicological Findings}

A Supelco (Bellefonte) SPME manual fiber assembly with fused-silica ( $85 \mu \mathrm{m}$ film thickness) carboxen-polydimethylsiloxanecoated (PDMS) was used for all analysis.

The standards of toluene, toluene $\mathrm{D}_{8}(99.96 \%)$ and o-, m-, p-xylenes (99.8\%) were obtained from Sigma-Aldrich (Germany). All of the reagents used in this study were of HPLC grade. Water and acetonitrile were bought from Fluka (Germany).

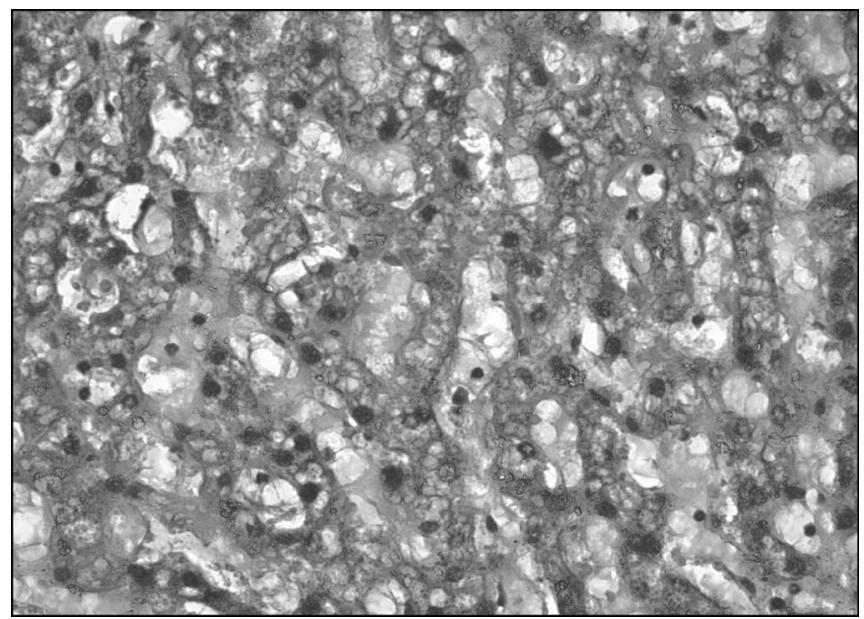

FIGURE 2. (EE 400×) Hepatic parenchyma showing diffuse vacuolar degeneration of hepatocytes and sinusoidal congestion.

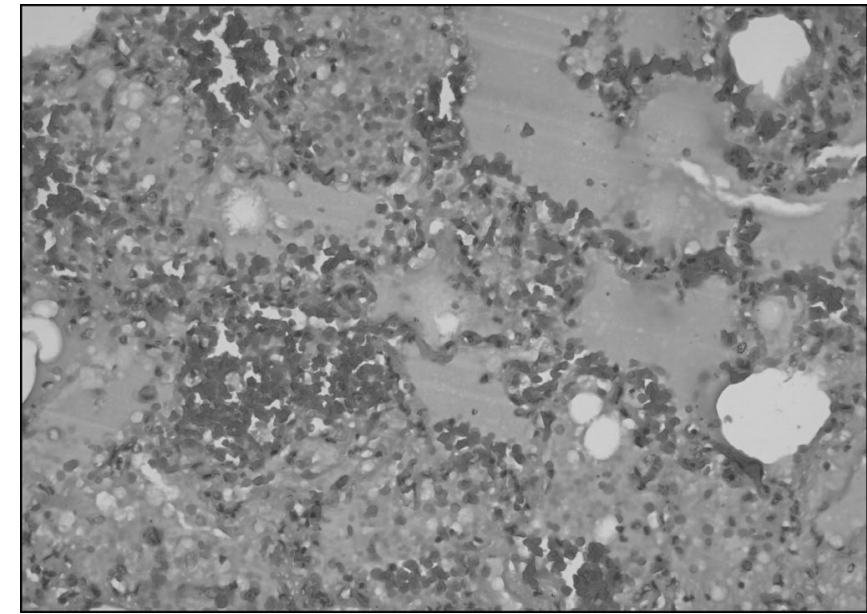

FIGURE 3. (EE 200×) Pulmonary parenchyma with alveolar edema and acute alveolar hemorrhage.

Determination and quantitation of volatile substances was performed by HS/Solid-Phase Microextraction/Gas ChromatographyMass Spectrometry (HS-SPME-GC/MS).

Analyses were carried out with GC/MS equipped with a column Supelcowax $10 \mathrm{TM}(30 \mathrm{~m} \times 0.25 \mathrm{~mm}$ ID, $0.25 \mu \mathrm{m}$ film thickness-Supelco).

\section{Headspace SPME Sampling Procedure}

All of the results of postmortem samples were stored at $-20^{\circ} \mathrm{C}$ up to the analysis. Extraction of volatiles was first optimized by choice of fiber. Several studies showed that Carboxen/PDMS coated fibers have been employed for biomonitoring of benzene and toluene in human blood. ${ }^{13}$ However in the preliminary studies, extractive capacity of Carboxen/PDMS (CAR/PDMS) and PDMS fibers was evaluated, and CAR/PDMS gave the highest level of these substances. ${ }^{14,15}$

The equilibration and adsorption times were established after several tests on samples of blood, liver, lung, kidneys, and gastric content (Table 1).

Based on the preliminary experiments, all of samples up to the analysis were kept at a temperature of $40^{\circ} \mathrm{C} \pm 0.5^{\circ} \mathrm{C}$ in aluminum block-heater for 1 hour.

\section{Instrument Conditions and GC-MS Analysis}

A preliminary study on gastric content as well as toxic determination in gastric content and blood were conducted using a single quadrupole instrument (HP 5890-Hewlett Packard).

Afterward, the analyses on the other tissue samples (liver, kidney, and lungs) were performed using a Varian STAR 3400 CX GC coupled with an ion trap MS analyzer (Varian Saturn 3 GC-MS)

TABLE 1. Equilibration and Desorption Time in the Various Tissues

\begin{tabular}{lcc}
\hline Matrices & Equilibration Time & Adsorption Time \\
\hline Blood & $10 \mathrm{~min}$ & $2 \mathrm{~min}$ \\
Gastric content & $30 \mathrm{~min}$ & $60 \mathrm{~min}$ \\
Liver & $30 \mathrm{~min}$ & $60 \mathrm{~min}$ \\
Kidney & $30 \mathrm{~min}$ & $30 \mathrm{~min}$ \\
Lung & $30 \mathrm{~min}$ & $60 \mathrm{~min}$ \\
\hline
\end{tabular}


and an autosampler (Varian $8200 \mathrm{CX}$ ), to achieve a better reproducibility on data and reduce manual errors.

The SPME fiber was placed into a injector (splitless mode) and the injection temperature was $260^{\circ} \mathrm{C}$. Carrier gas flow was 35 $\mathrm{cm} / \mathrm{s}$, column pressure was $56 \mathrm{KPa}$, the oven program condition were the following: isotherm $50^{\circ} \mathrm{C}$ for 12 minutes, ramp up to $250^{\circ} \mathrm{C}$ at $40^{\circ} \mathrm{C} / \mathrm{min}$, isotherm at $250^{\circ} \mathrm{C}$ for 3 minutes

The EI/MS spectra $(70 \mathrm{eV})$ were carried out operating in SIM mode and as extracted ions, using respectively a single quadrupole instrument and ITD mass analyzer. In both instruments, full scan mode was used as an identification test. Scan time was fixed on 1 second Monitored ions were $\mathrm{m} / \mathrm{z} 78$ (benzene); $\mathrm{m} / \mathrm{z} 98$ (toluene $\mathrm{D}_{8}$ ); $\mathrm{m} / \mathrm{z} 91$ (toluene); and m/z 91, m/z 106 (xylenes).

To assess the reproducibility of the analysis, each sample was analyzed 3 times.

The preliminary analysis allowed an estimate of the amount of the various analytes in the different matrices, in this way, it was possible to determine the amount of standard addition.

Liquid samples and particularly blood and gastric fluid were analyzed using the multiple standard addition method, to reduce to the minimum the matrix effect. For the solid samples, frozen kidney and liver quantification was performed using a calibration curve toluene $\mathrm{D}_{8}$ as internal standard.

The general approach was to optimize the method to avoid as possible analyte losses, minimizing sample manipulation. This required a different approach, depending on the tissues analyzed to obtain the best accuracy of measure. However, similar chromatographic results were obtained for all the samples and both quadrupole and ITD/MS. A typical example is reported in Figure 4.

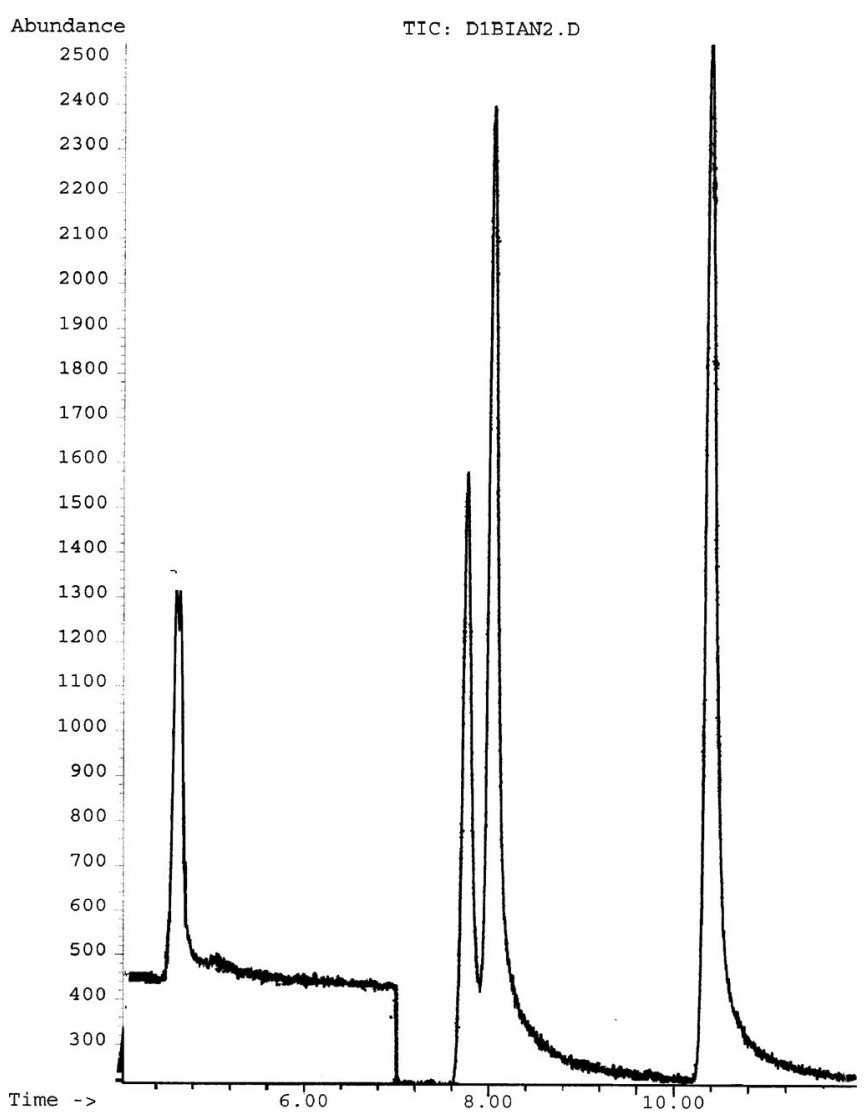

FIGURE 4. Selected ion chromatogram of toluene, paraxylene, meta-xylene, ortho-xylene.

\section{Gastric Content}

Four identical vials containing $455 \mu \mathrm{L}$ of samples were prepared. In each one an aliquot of $20 \mu \mathrm{L}$ of internal standard (Toluene $\mathrm{D}_{8}$ at concentration $2000 \mathrm{ppm}$ ) was added. Further, an appropriate amount of standard solution was added to obtain a final standard concentration of 500, 1000, and $2000 \mathrm{ppb}$ of toluene; 150, 300 , and $600 \mathrm{ppb}$ of ortho- and meta-xylene; and 50, 100, and 200 $\mathrm{ppb}$ of para-xylene, respectively, in the final volume of $600 \mu \mathrm{L}$. This was obtained by further diluting the sample with HPLC grade water.

\section{Blood}

Four vials $(2 \mathrm{~mL})$ containing $0.5 \mathrm{~g}$ of sample were prepared. To each one an aliquot of $5 \mu \mathrm{L}$ of internal standard (benzene at concentration $200 \mathrm{ppm}$ ) was added.

An appropriate amount of standard solution was added to obtain a final standard concentration of $5,10,15 \mathrm{ppb}$ of toluene; ortho-, meta-, and para-xylene in the final volume of $1 \mathrm{~g}$.

This was obtained by further diluting the sample with HPLC grade water.

\section{Liver, Kidney, and Lung}

In this case, sample handling was particularly difficult due to the volatility of the analytes and the intrinsic nature of the matrix. For such solid samples, a homogenization process was necessary, which was conducted in ice bath to avoid significant volatile losses. Even cautiously homogenized, the samples were difficult to manage. It was particularly difficult to weight small amounts necessary for autosampler vials and perform for each sample a multiple standard addition. Several attempts were made but the method adopted lacked of precision, results obtained were used as an estimate of the levels of toxic in the liver, kidney, and lung tissues. A new strategy for these samples was then adopted and quantification was made through and external calibration curve. To minimize the errors due to matrix effect, the calibration curve was generated trough a spiked simulated.

Matrix made ad hoc for each tissue analyzed. Thus, homogenized porcine liver, bovine lung, and kidney were used as matrices. Further, for better accuracy, toluene $\mathrm{D}_{8}$ was adopted, as internal standard. For lung, the preliminary study confirmed that concentration levels were well below the quantification level and for several analytes no analytical signal was detected. Instead for the liver and kidney, this study revealed as raw estimate the concentrations levels of the analytes, as well as their relative abundances; for these tissues the detailed analysis procedure is reported below.

The animal samples (liver and kidney) have been frozen at $-23^{\circ} \mathrm{C}$ for 1 week (with the aim to better simulate postmortem samples) and afterward have been homogenized in ice bath.

A standard mix (A) solution containing toluene at about 1000 ppm (100 $\mu \mathrm{L}$ in $100 \mathrm{~mL}$ water/acetonitrile 60:40), ortho- and meta-xylene at $330 \mathrm{ppm}(33 \mu \mathrm{L}$ in $100 \mathrm{~mL}$ water/acetonitrile $60: 40)$ and para-xylene at $100 \mathrm{ppm}(10 \mu \mathrm{L}$ in $100 \mathrm{~mL}$ water/acetonitrile 60:40) was prepared to be added to liver samples.

Another standard mix (B) solution containing toluene at about $25 \mathrm{ppm}(25 \mu \mathrm{L}$ in $100 \mathrm{~mL}$ water/acetonitrile 60:40), para-xylene at about $25 \mathrm{ppm}(25 \mu \mathrm{L}$ in $100 \mathrm{~mL}$ water/acetonitrile 60:40), metaxylene and ortho-xylene at about $100 \mathrm{ppm}(100 \mu \mathrm{L}$ in $100 \mathrm{~mL}$ water/acetonitrile 60:40) was prepared to be added to kidney samples. As it can be seen, the standard solutions have been prepared volumetrically, therefore, the following concentrations reported in ppm are corrected for toluene, ortho-, meta-, and para xylene density.

For the calibration curve, aliquots of $600 \mathrm{mg}$ of homogenate were prepared and, in each sample, an appropriate aliquot of standard mix solution (A for liver and B for kidney) (Table 2) was added. 
TABLE 2. Standard Amounts in the 4 Aliquots of Liver and Kidney Samples

\begin{tabular}{|c|c|c|c|c|}
\hline \multirow[b]{2}{*}{ Matrices } & \multicolumn{4}{|c|}{ Calibration Levels $\mu \mathrm{g}(\mathrm{ppm})$ of Substances in $600 \mathrm{mg}$ of Animal Tissue } \\
\hline & Analytes & $1(25 \mu \mathrm{L}$ Std Mix A) & $2(100 \mu \mathrm{L}$ Std Mix A) & $3(200 \mu \mathrm{L}$ Std Mix A) \\
\hline \multirow[t]{3}{*}{ Liver } & Toluene & $21.6(35.9)$ & $86.4(144)$ & $173(289)$ \\
\hline & $\begin{array}{l}\text { o-xylene } \\
\text { m-xylene }\end{array}$ & $7.26(12.1)$ & $28.6(47.6)$ & $57.6(96.0)$ \\
\hline & p-xylene & $\begin{array}{c}2.15(3.59) \\
(25 \mu \mathrm{L} \text { Std Mix B })\end{array}$ & $\begin{array}{c}8.55(14.3) \\
(50 \mu \mathrm{L} \text { Std Mix B) }\end{array}$ & $\begin{array}{c}17.3 \text { (28.9) } \\
(200 \mu \mathrm{L} \text { Std Mix A) }\end{array}$ \\
\hline \multirow[t]{3}{*}{ Kidney } & Toluene & $0.540(0.900)$ & $1.08(1.80)$ & $4.32(7.20)$ \\
\hline & p-xylene & $0.542(0.903)$ & $1.08(1.81)$ & $4.33(7.22)$ \\
\hline & $\begin{array}{l}\text { o-xylene } \\
\text { m-xylene }\end{array}$ & $2.16(3.60)$ & $4.33(7.22)$ & $17.28(28.8)$ \\
\hline
\end{tabular}
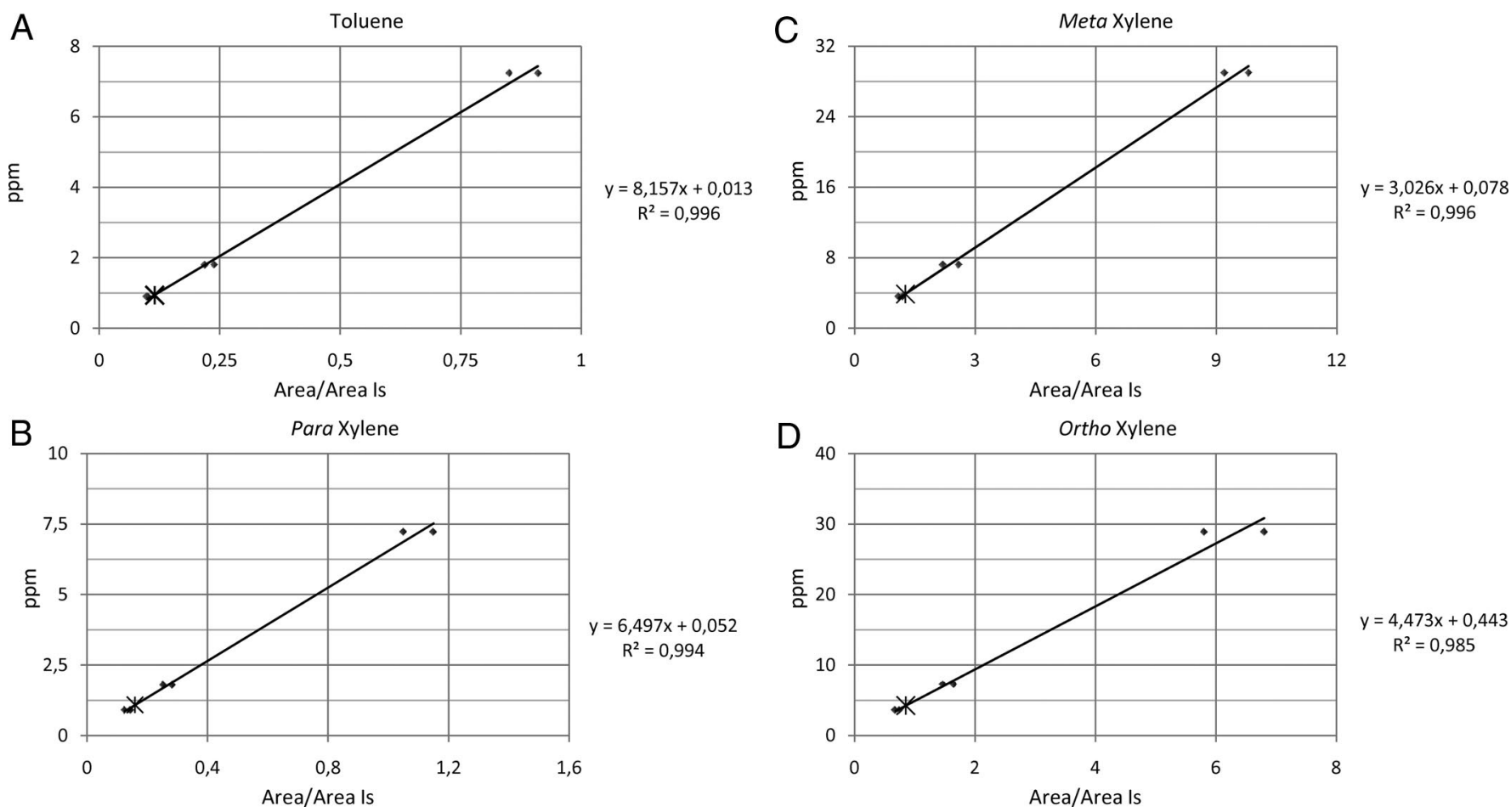

FIGURE 5. Calibration curves obtained for toluene (A), para- (B), meta- (C), and ortho-xylene (D) in liver, the stars indicates sample concentration reported on the regression curve.

The samples were further diluted to $30 \mathrm{~mL}$ (for liver) and to $10 \mathrm{~mL}$ (for kidney) using HPLC grade water, and vortex mixed for 1 minute. Vials containing $200 \mu \mathrm{L}$ of diluted samples added with 20 $\mu \mathrm{L}$ of internal standard solution (toluene- $\mathrm{D}_{8} 2000 \mathrm{ppm}$ in water/ CH3CN 60:40) were finally used for analysis.

Calibration curves obtained reporting concentration versus standard/internal standard area ratio are shown in Figure 5. Calibration levels were optimized to achieve at least one point of the calibration curve in proximity of the expected concentration for each toxic in the tissue, few concentration levels per curve were taken into consideration as it was known the order of magnitude of analytes. Each measure was repeated twice to check the reproducibility.

Human samples were homogenized and $600 \mathrm{mg}$ of tissue homogenate was diluted to $30 \mathrm{~mL}$ (for liver) and to $10 \mathrm{~mL}$ (for kidney) using HPLC water; vials were prepared using $200 \mu \mathrm{L}$ of diluted sample added with $20 \mu \mathrm{L}$ of internal standard solution (toluene- $\mathrm{D}_{8} 2000 \mathrm{ppm}$ in water/CH3CN 60:40). Results are reported in Table 3.

\section{DISCUSSION}

Organic compounds are distributed throughout analyzed tissues reflecting the greatest affinity for lipid-rich tissues such as liver and kidney instead that for blood (Table 2).

Gastric content showed very high concentration of toxics, even if a relevant part of ingested solvents were also distributed in body tissues. The highest concentration of solvents was in liver according to lipophilic nature of analyzed parenchyma.

Within kidney toluene concentration was lower than xylenes concentration.

Only a few concentration $(<\mathrm{LOQ})$ of organic compounds were detected in lung, probably because of reanimation, time passed between autopsy and ingestion, and also the wide exchange surface of pulmonary tissue.

Quite surprisingly, just in blood (Fig. 6), the presence of further aromatic compound was exploited. This was identified as 
TABLE 3. VOCs Concentration in the Various Tissues in ppm

\begin{tabular}{lcccc}
\hline Sample & Toluene ppm & Ortho-Xylene ppm & Meta-Xylene ppm & Para-Xylene ppm \\
\hline Gastric content & 21,500 & 1500 & 1075 & 5400 \\
Blood & 0.060 & 0.232 & 0.160 & 0.065 \\
Liver & 41.5 & 12 & 15 & 6 \\
Kidney & 0.939 & 4.15 & 3.86 & 1.08 \\
Lung & $<$ LOQ & $<$ LOQ & $<$ LOQ & $<$ LOQ \\
\hline
\end{tabular}

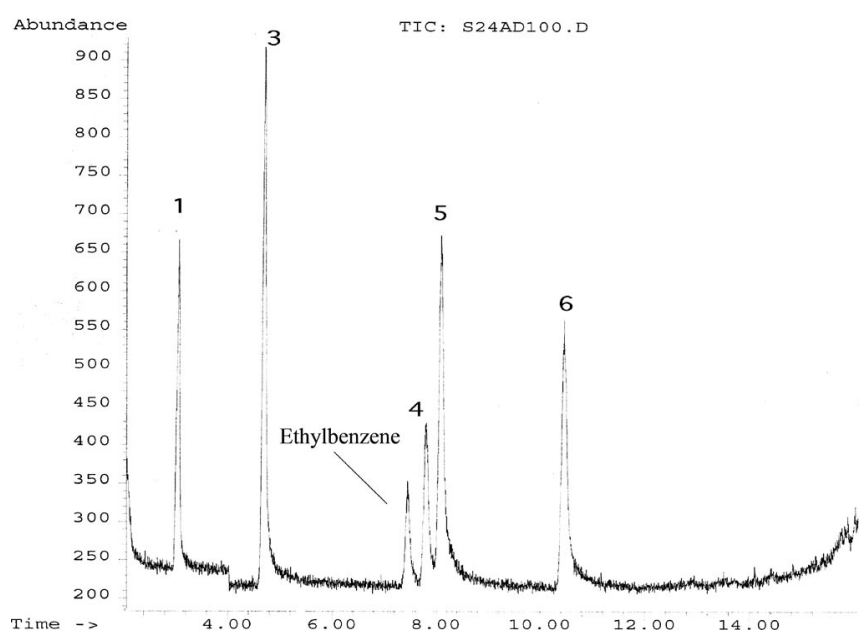

FIGURE 6. Chromatogram of a blood sample spiked with: 1 benzene, 3 toluene, 4 p-xylene, 5 m-xylene, 6 o-xylene.

ethylbenzene by mass spectrum and research in Nist 02 library. The presence of ethylbenzene was revealed only in blood, none of the other tissues under investigation revealed traces of this organic compound. We, up to now, have not explanation for the presence of this further contaminant since all standard have been checked to verify its presence even as trace contaminant. Ethylbenzene was found neither in liver and kidney and, most surprisingly, neither in gastric content, were concentration of the solvents was much higher.

Because of their lipophilic character, volatiles have a serious impact in the brain and in other parts of the nervous system. They act as a central nervous system depressant and this is the most common cause of death in VOC's ingestion. The lipid solubility, volatility, and route of exposure of the compounds enhance their toxicity. ${ }^{16}$ The most important toxicological effects are observed for the heart, brain and neurologic system, liver, kidney, and lungs. ${ }^{17}$

Little is known about the mechanisms by which toluene produces acute effects but it is reasonable to assume that its toxic effects are due, at least in part, to its general characteristics as a solvent: the presence of solvent molecules in cholesterol-filled interstices between phospholipids and sphingolipids changes membrane fluidity, thereby altering intercellular communication and normal ion movements. ${ }^{18}$

An alternative hypothesis is that toluene partitions into hydrophobic regions of proteins and interacts with them, thereby altering membrane-bound enzyme activity and/or receptor specificity. ${ }^{19}$

Reports of oral exposure to toluene in humans are limited to case reports of accidental acute ingestion. In humans, a toluene ingestion (only few $\mathrm{mL}$ ) is fatal and death occurs after only 30 minutes. $^{20} \mathrm{~A}$ case report of a 51-year-old man who died approximately 30 minutes after he had ingested a large quantity of toluene $(625 \mathrm{mg} / \mathrm{kg})$ was presented; the probable cause of death was severe central nervous system depression, they also noted acute tubular necrosis and acidosis. ${ }^{21}$ Caravati and Bjerk $(1997)^{20}$ report on a nonlethal case of a 46-year-old man who had ingested approximately one-quarter of paint thinner containing toluene. The patient presented a severe central nervous system depression, severe abdominal pain, diarrheal, hemorrhagic gastritis, acute tubular necrosis, and acidosis. Human studies following oral exposure to xylenes are not available.

Abu-Al-Ragheb et al (1986) ${ }^{22}$ report on a 27-year-old man who committed suicide by ingesting xylenes. Histopathological findings included areas of pulmonary edema and congestion. The probable cause of death was attributed to respiratory failure and asphyxia, a secondary response elicited by depression in the respiratory center in the brain.

In another case, accidental ingestion of xylenes resulted in a deep coma lasting more than 26 hours, hepatic impairment, hematemesis, acute pulmonary edema, and other pulmonary complications. ${ }^{23}$

Our case showed multiorgan damage and diffuse cytotoxic edema. The probable cause of death was attributed to acute toxics effect as solvent in body, and to pulmonary complications, respiratory failure, depression in the respiratory center, and extensive cerebral edema.

\section{CONCLUSIONS}

The case study finding provides additional support to the proposal that fatal intoxication by ingestion of aromatic solvents can occur in a subject having suicidal intent.

Moreover, the comparison of histologic and toxicological findings provides to understand correlation between organic damage following ingestion and amounts of solvents found. Findings in toxic concentration in various tissues indicate that the distribution of toxic is related to their lipophilicity. However, in lung concentration of solvents was particularly low and far below to the limit of quantization of the method. This imply a small partition of the toxic in lung otherwise that lung large exchange surface or the reanimation processes or both of them could be responsible of the elimination of these solvents in this tissue.

\section{REFERENCES}

1. Toxicological Review of toluene EPA/635/R-05/004.

2. Toxicological Review of Xylenes, EPA 635/R-03/001.

3. Wille SM, Lambert WE. Volatile substance abuse-post mortem diagnosis. Forensic Sci Int. 2004;142:135-156.

4. Seto Y. Determination of volatile substances in biological samples by headspace gas-chromatography. J Chromatogr A. 1994;674:25-62.

5. Cardinali FL, McCraw JM, Ashley DL, et al. Production of blank water for the analysis of volatile organic compounds in human blood at the low parts-per-trillion level. J Chromatogr Sci. 1994;32:41-45.

6. Gill R, Hatchett SE, Osselton MD, et al. Sample handling and storage for the quantitative analysis of volatile compounds in blood - the determination of toluene by headspace gas-chromatography. J Anal Toxicol. 1988; $12: 141-146$

7. Flanagan RJ, Streete PJ, Rampsey JD. Practical guideline for analytical investigation of suspected cases and interpretation of results. Available at: http://www.unodc.org/pdf/technical_series_1997-01-01_1.pdf.

8. Streete PJ, Ruprah M, Ramsey JD, et al. Detection and identification of 
volatile substances by headspace capillary gas-chromatography to aid the diagnosis of acute-poisoning. Analyst. 1992;117:1111-1127.

9. Dyne D, Cocker J, Streete PJ, et al. Toluene, 1- butanol, ethylbenzene and xylene from Sarstedt Monovette serum gel blood collection tubes. Ann Clin Biochem. 1996;33:355-356

10. Streete PJ, Flanagan RJ. Ethylbenzene and xylene from Sarstedt Monovette serum gel blood-collection tubes. Clin Chem. 1993;39:1344-1345.

11. Arthur CL, Pawliszyn J. Solids phase microextraction with thermal desorption using fused silica optical fibers. Anal Chem. 1990;62:2145-2148.

12. Zhang Z, Pawliszyn J. Headspace solids-phase microextraction. Anal Chem. 1993;65:1843-1852.

13. Schimming F, Levseo K, Kohme C, et al. Biomonitoring of benzene and toluene in human blood by headspace-solid-phase microextraction. Fresenius J Anal Chem. 1999;363:88-91.

14. Paschke A, Popp P. Diffusion-based calibration for solid-phase microextraction of benzene, toluene, ethylbenzene, $\mathrm{p}$-xylene and chlorobenzenes from aqueous samples. $J$ Chromatogr A. 2004;1025:11-16.

15. Lee XP, Kumazawa T, Kondo K, et al. Improved extraction of thinner components from human body fluids by headspace solid-phase microextrac- tion with a carboxen/polydimethylsiloxane-coated fiber. Leg Med. 1999;1: 231

16. Kurtzman TL, Otsuka KN, Wahl RA. Inhalant abuse by adolescents. $J$ Adolesc Health. 2001;28:170-180.

17. Leikin JB. Substance-related disorders in adults. Dis Mon. 2007;53:313-335.

18. Engelke M, Tahti H, Vaalavirta L. Perturbation of artificial and biological membranes by organic compounds of aliphatic, alicyclic, and aromatic structure. Toxicol In Vitro. 1996;10:111-115.

19. Balster RL. Neural basis of inhalant abuse. Drug Alcohol Depend. 1998;512 207-214.

20. Caravati EM, Bjerk PJ. Acute toluene ingestion toxicity. Ann Emerg Med. 1997;30:838-839.

21. Ameno K, Fuke C, Ameno S, et al. A fatal case of oral ingestion of toluene. Forensic Sci Int. 1989;41:255-260.

22. Abu-Al-Ragheb S, Salhab AS, Amr SS. Suicide by xylene ingestion: A case report and review of literature. Am J Forensic Med Pathol. 1986;7:327-329.

23. Recchia G, Perbelline L, Prati GF, et al. Coma da probabile ingestione accidentale di xilene: trattamento mediante emoperfusione con carbone attivato. Med Lav. 1985;76:67-73. 